Article

\title{
Investigation on the Thermal Effects of WC-Co Turning Inserts Deposited by Additive Manufacturing of Titanium Alloy Powder
}

\author{
Joon-Koo Park ${ }^{1}$, Choon-Man Lee ${ }^{2, *(D)}$ and Dong-Hyeon Kim ${ }^{3, *}$ (D) \\ 1 School of Smart Manufacturing Engineering, Changwon National University, Changwon 51140, Korea; \\ koo94@changwon.ac.kr \\ 2 Department of Mechanical Engineering, Changwon National University, Changwon 51140, Korea \\ 3 Mechatronics Research Center, Changwon National University, Changwon 51140, Korea \\ * Correspondence: cmlee@changwon.ac.kr (C.-M.L.); dkim@changwon.ac.kr (D.-H.K.)
}

check for updates

Citation: Park, J.-K.; Lee, C.-M.; Kim, D.-H. Investigation on the Thermal Effects of WC-Co Turning Inserts Deposited by Additive Manufacturing of Titanium Alloy Powder. Metals 2021, 11, 1705. https://doi.org/ $10.3390 /$ met11111705

Academic Editor: Ilya Okulov

Received: 24 September 2021

Accepted: 24 October 2021

Published: 26 October 2021

Publisher's Note: MDPI stays neutral with regard to jurisdictional claims in published maps and institutional affiliations.

Copyright: (c) 2021 by the authors. Licensee MDPI, Basel, Switzerland. This article is an open access article distributed under the terms and conditions of the Creative Commons Attribution (CC BY) license (https:// creativecommons.org/licenses/by/ $4.0 /)$.

\begin{abstract}
Metal additive manufacturing (AM) has been one of the most useful processes in the manufacturing field. It has significant advantages in terms of the benefits of feature freedom and material waste reduction. These processes commonly use a heat source to fabricate a 3D shape through melting of a metal powder and subsequent solidification. The directed energy deposition method can stack the desired amount of material in the required location. This study addresses the thermal effects of a WC-Co cutting tool insert deposited by AM of titanium alloy powder in the turning process. First, the optimal deposition conditions were selected by conducting preliminary experiments. Second, titanium alloy powder was deposited on the turning insert under the selected conditions. Finally, verification evaluation was carried out in the turning process. The thermal effects of the turning insert with the titanium alloy were compared with an ordinary cutting tool insert. The average temperature of the cutting tool was reduced by $15 \%$ during operation.
\end{abstract}

Keywords: additive manufacturing; directed energy deposition; cutting tools; turning process; titanium alloy

\section{Introduction}

Manufacturing processes affect a large portion of industrial sites owing to their complexity, productivity, and achievable shape and dimensional accuracy [1]. Additive manufacturing (AM) is a process for making freely formed parts by adding material layerby-layer in an efficient way [2]. Compared to traditional manufacturing processes, AM techniques can lead to significant business benefits, such as time and cost savings due to tooling reduction, virtually unlimited geometric complexity and less waste production [3]. This means that production can be completed within limited cost and deadline constraints. Powder bed fusion (PBF) and direct energy deposition (DED) are the most frequently used AM techniques for the fabrication of metal products [4]. The DED process is a class of AM processes that implements a focused thermal energy source, such as a laser, arc, plasma, electric beam, etc. to melt deposited material [5].

In general, cutting tools consist of various materials and types and are constructed to satisfy the geometric needs for machining specific combinations of workpiece materials. These tools not only interface with a manufacturer's current system and setup but also provide a surface finish. Without buying these expensive tools for application-specific tasks, production companies are often forced to use multiple inexpensive tools to balance production schedules and costs. Although available tool materials, designs and concepts have been developed over the years to promote cost reduction, extended life and ease of tool change in case of failure, high cost remains a challenge. In the sintering process, it is difficult to immediately reflect the design because it requires a frame that fits the 
shape to make the desired feature. In contrast, the AM process can produce more than the specified shapes in the production process. In contrast to the sintering process, the advantage of AM is that it is suitable for the small production of modern multispecies. Traxel and Bandyopadhyay manufactured diamond-reinforced carbide structures via the DED process [6]. Leal et al. investigated AM tooling for the automotive industry [7]. Klocke et al. summarized the definition and classification of AM processes according to ASTM Standard F 2792-12a and reviewed laser AM for hot-work tool steels [2]. Fotovvati and Asadi investigated the size effects on geometrical accuracy for AM of Ti-6Al-4V ELI parts. [8]. Ma et al. performed a 3D numerical investigation of a microgroove textured cutting tool in the dry machining of titanium alloys [9]. Guimarães et al. performed a novel cemented carbide cutting tool design and fabrication process to enhance the thermal conductivity of these tools [10]. Kustas et al. performed nanocoatings on cutting tools for dry machining [11]. List et al. investigated the wear behavior of cemented carbide tools in dry machining [12]. Kim et al. reviewed and summarized machining processes using machine learning algorithms and suggested a perspective on the machining industry [13]. Devaraj et al. performed a performance analysis of micro-textured cutting insert design parameters for machining Al-MMC in the turning process [14]. Yan et al. performed continuum model-based chatter stability prediction for highly flexible parts in the turning process with accurate dynamic force modeling [15]. Kam et al. performed an analysis of tool vibration and surface roughness during the turning process of tempered steel samples using the Taguchi method [16]. Franchi et al. studied the numerical thermal characterization of a 3D turning process of SAF 2507 stainless steel [17]. Gupta et al. performed tribological performance-based machinability investigations in the cryogenic cooling-assisted turning of $\alpha-\beta$ titanium alloys [18]. Kolluri et al. evaluated the thermal effects in turning processes using numerical and experimental approaches [19].

Many researchers in the AM area have studied the feasibility of DED with titanium alloy powder. Researchers in the cutting area are working on the development of the cutting tool to improve tool life and its performance. In the same context, this study deals with both areas. The thermal effects of WC-Co cutting tool inserts deposited by using the DED process of titanium alloy powder in the turning process were investigated. The process enables the stack desired amount of material in the required location. Titanium alloy can reduce heat generation during cutting by using low thermal conductivity. This study demonstrates the evaluation of deposited titanium alloy in the first section. In Section 2, the simulation was performed with FE methods for predicting the thermal effect of the material. In Section 3, a verification experiment was performed to verify the effect of reducing the cutting heat.

\section{Materials and Methods}

\subsection{Materials}

Titanium alloy powder (Grade $5 \mathrm{Ti}-6 \mathrm{Al}-4 \mathrm{~V}$ ) was used as a deposition material in this study. Titanium alloy has lightweight and corrosion resistance, heat resistance. In general, WC-Co cutting tools become brittle and brittle at high temperatures. Titanium alloy is utilized to offset the disadvantages of WC-Co cutting tools. Figure 1 shows a scanning electron microscopy (SEM) image of the material. Spherical titanium alloy powder with particle sizes of approximately $50-150 \mu \mathrm{m}$ or less was used. Table 1 shows the chemical composition of the powder used in the DED process. 


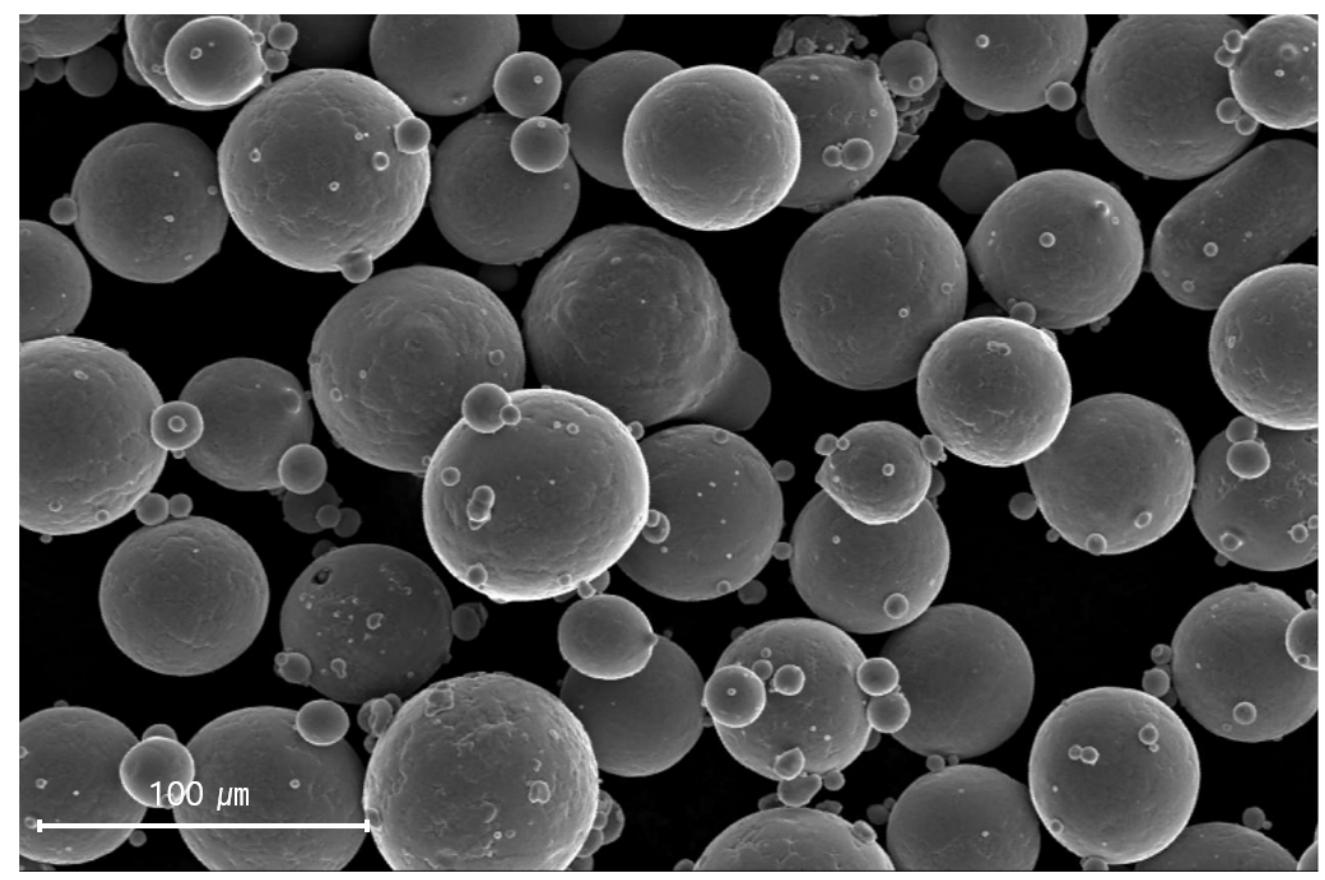

Figure 1. SEM image of Ti-6Al-4V.

Table 1. Chemical composition of the titanium alloy powder.

\begin{tabular}{ccccccccc}
\hline Element & Al & $\mathbf{C}$ & Fe & V & N & O & H & Ti \\
\hline wt. $\%$ & 6.5000 & 0.0260 & 0.1500 & 4.3000 & 0.0030 & 0.1800 & 0.0010 & Bal. \\
\hline
\end{tabular}

\subsection{Method}

The WC-Co cutting tool was used in the turning process and was compared with the cutting tool deposited with a titanium alloy. The experimental parameters are provided in Table 2.

Table 2. Experimental parameters.

\begin{tabular}{cc}
\hline Parameters & Levels \\
\hline Laser power $(\mathrm{kW})$ & $0.6,0.8,1.0$ \\
Travel speed $(\mathrm{mm} / \mathrm{min})$ & $250,275,300$ \\
Powder feed rate $(\mathrm{g} / \mathrm{min})$ & 14,16 \\
\hline
\end{tabular}

Figure 2a shows the schematic diagram of the DED process. The deposition method is shown in Figure $2 \mathrm{~b}$. The numbers indicate the additive manufacturing process temporal sequence. It is the strategy on the WC-Co cutting tool for applying titanium alloy. The cutting tool measuring $12.5 \mathrm{~mm}$ wide and $4.95 \mathrm{~mm}$ long. Titanium alloy was deposited on the upper surface of the WC-Co cutting tool, and two surfaces near the deposited surface were deposited. Titanium alloy powder was deposited $3 \mathrm{~mm}$ in $x, y$-direction, in the $\mathrm{z}$-direction, titanium alloy powder was deposited by $1 \mathrm{~mm}$.

The experimental setup for AM of titanium alloys was set, as shown in Figure 3. Figure $3 a$ is DED AM machine Figure $3 b$ is the chiller for cooling the DED AM machine, Figure $3 c$ is powder feeder for transfer titanium alloy powder, Figure $3 d$ is the shield gas $(\mathrm{Ar})$ and transfer gas $(\mathrm{N})$. Figure $3 \mathrm{e}$ is computer for control DED AM machine. Figure $3 \mathrm{f}$ is high power diode laser. 


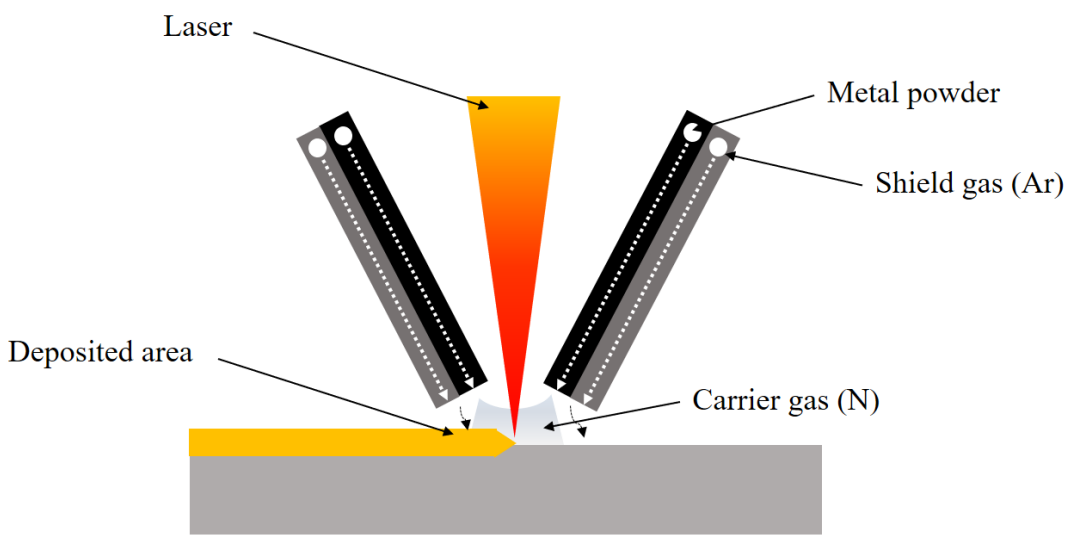

(a)

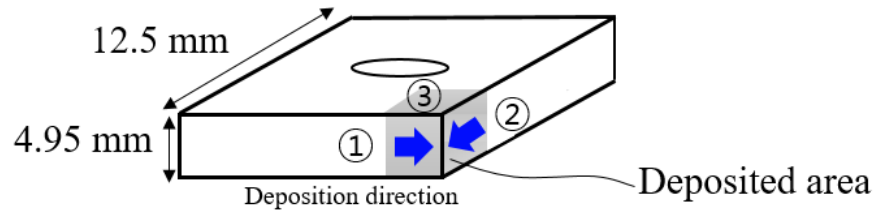

(b)

Figure 2. Schematic diagram of the direct energy deposition (DED) process (a) and titanium alloy powder deposited WC-Co cutting tool insert (b).
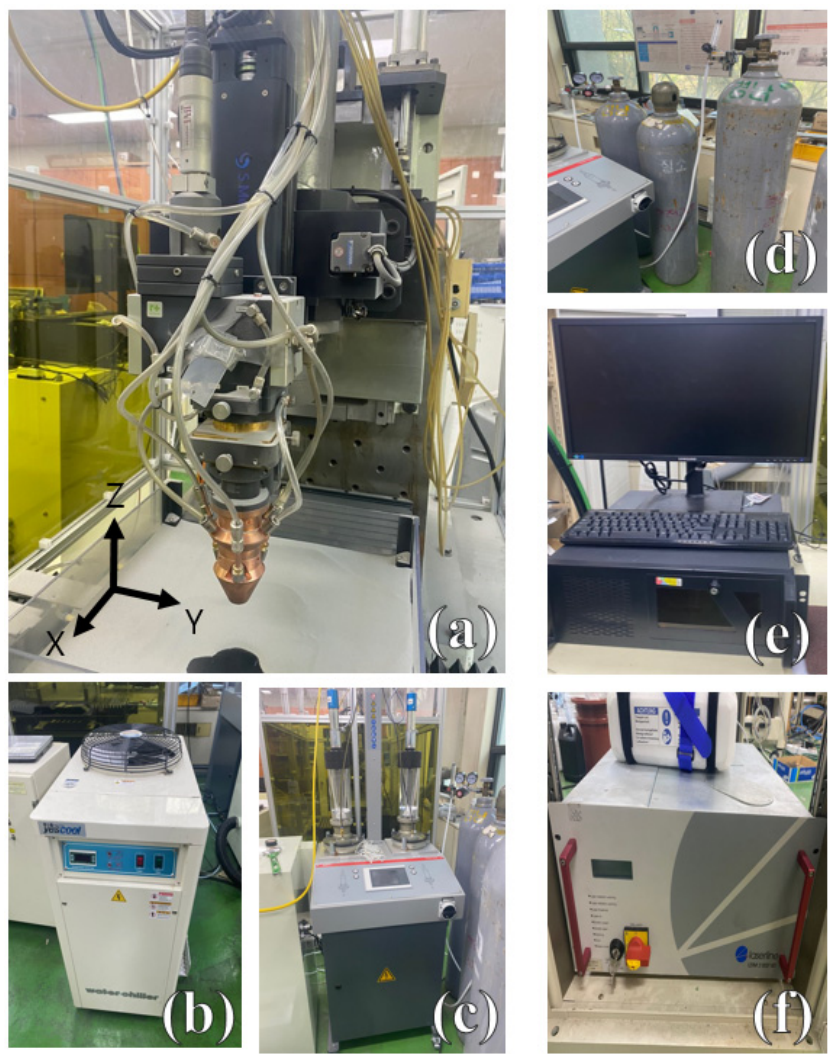

Figure 3. Experimental setup: (a) AM system; (b) water chiller; (c) powder feeder; (d) argon gas and nitrogen gas; (e) control computer; and (f) $2 \mathrm{~kW}$ diode laser.

\section{Additive Manufacturing of Titanium Alloy Powder}

The DED process was performed on a plate to evaluate the hardness of the deposited titanium alloy. The experimental conditions used were the same conditions specified in Table 2. For the microstructure measurement of the AM specimens, polishing work was 
carried out after section cutting. SiC sandpaper (220 to 2000 grit) was used in the polishing process. A titanium-only etching solution was used for an etching operation of approximately $1 \mathrm{~min}$. The produced specimen was analyzed through SEM. Microstructure analysis using a microscope was performed. The microstructure was measured by observing crosssections of deposited specimens. Figure 4 shows the microstructures of the deposited titanium alloy specimens. All the deposited specimens were cooled by air at room temperature. Cracks, porosity, and oxidation were found in the titanium alloys deposited at $800 \mathrm{~W}$ and $900 \mathrm{~W}$. On the other hand, in the titanium alloy deposited with $1000 \mathrm{~W}$, a relatively fine microstructure and grain boundaries were observed. Titanium alloy deposited with $1000 \mathrm{~W}$ was completely melted compared to $900 \mathrm{~W}$. In addition to Figure $4 \mathrm{a}$, microstructures of all the deposited titanium alloys were observed with characteristic stretchy spine microstructures. In Figure $4 \mathrm{a}$, oxide and porosity defects occurred due to oxidation cracks. Figure $4 a-d$ show cracks and oxides. However, in Figure 4e, defects, such as cracks, porosity and oxidation, are not evident. Nonuniform cooling after deposition will result in defects, such as cracks, porosity, and oxides. The grain boundaries in Figure $4 \mathrm{~d}$,e appeared most clearly at a laser power of $1000 \mathrm{~W}$. Figure 5 shows the state of the titanium metal according to its vanadium content and temperature [20,21]. Referring to Figure 5, it can be seen that $\alpha$-titanium and $\beta$-titanium are detected at a temperature of $500{ }^{\circ} \mathrm{C}$ or higher.
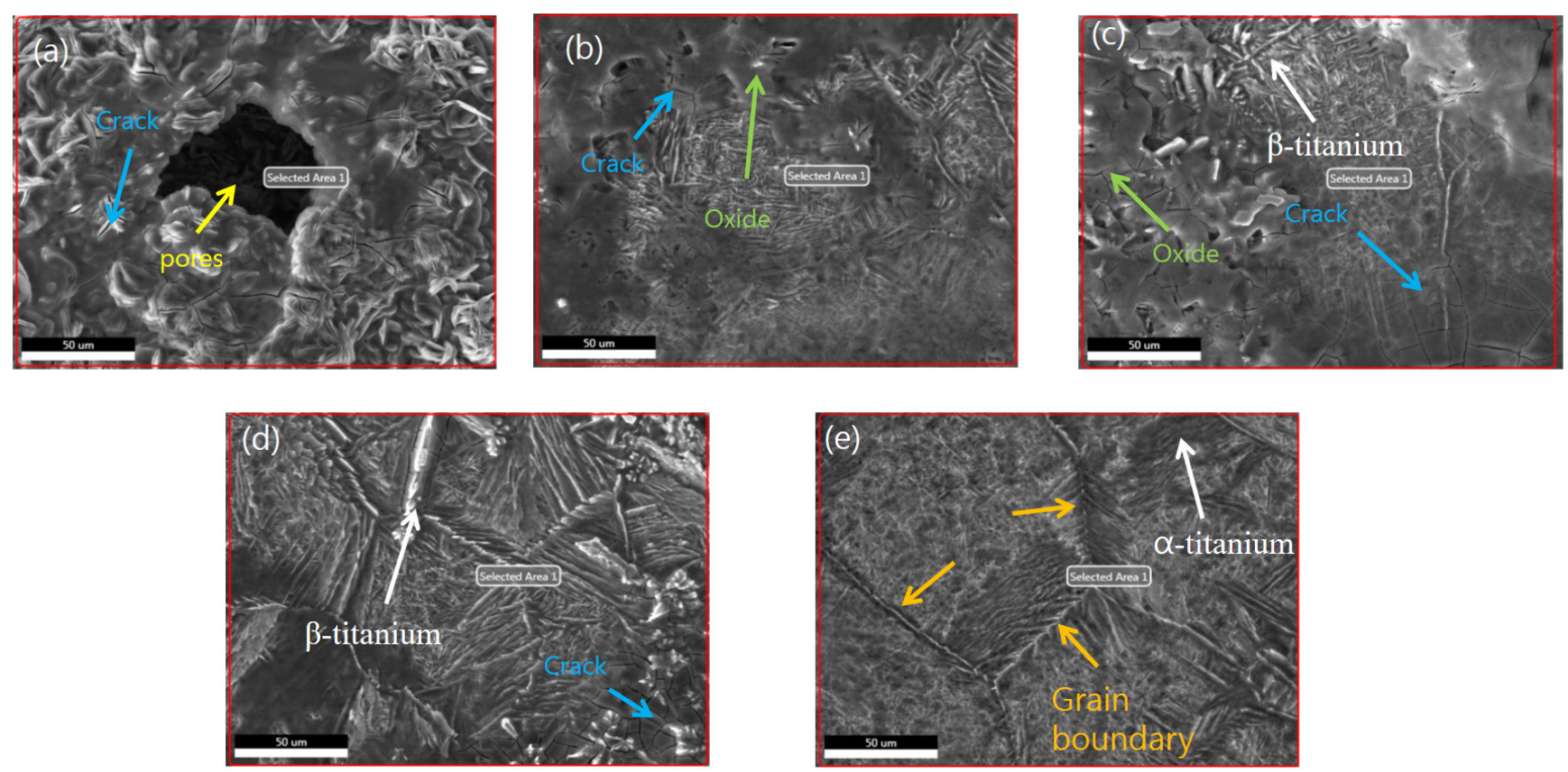

Figure 4. Microstructures of deposited titanium alloys $50 \mu \mathrm{m}$ : (a) Laser power: $800 \mathrm{~W}$, Powder feed rate: $14 \mathrm{~g} / \mathrm{min}$, Scan speed: $10 \mathrm{~mm} / \mathrm{s}$; (b) Laser power: $900 \mathrm{~W}$, Powder feed rate: $14 \mathrm{~g} / \mathrm{min}$, Scan speed: $10 \mathrm{~mm} / \mathrm{s}$; (c) Laser power: $900 \mathrm{~W}$, Powder feed rate: $16 \mathrm{~g} / \mathrm{min}$, Scan speed: $10 \mathrm{~mm} / \mathrm{s}$; (d) Laser power: $1000 \mathrm{~W}$, Powder feed rate: $14 \mathrm{~g} / \mathrm{min}$, Scan speed: $10 \mathrm{~mm} / \mathrm{s}$; and (e) Laser power: $1000 \mathrm{~W}$, Powder feed rate: $14 \mathrm{~g} / \mathrm{min}$, Scan speed: $11 \mathrm{~mm} / \mathrm{s}$. 


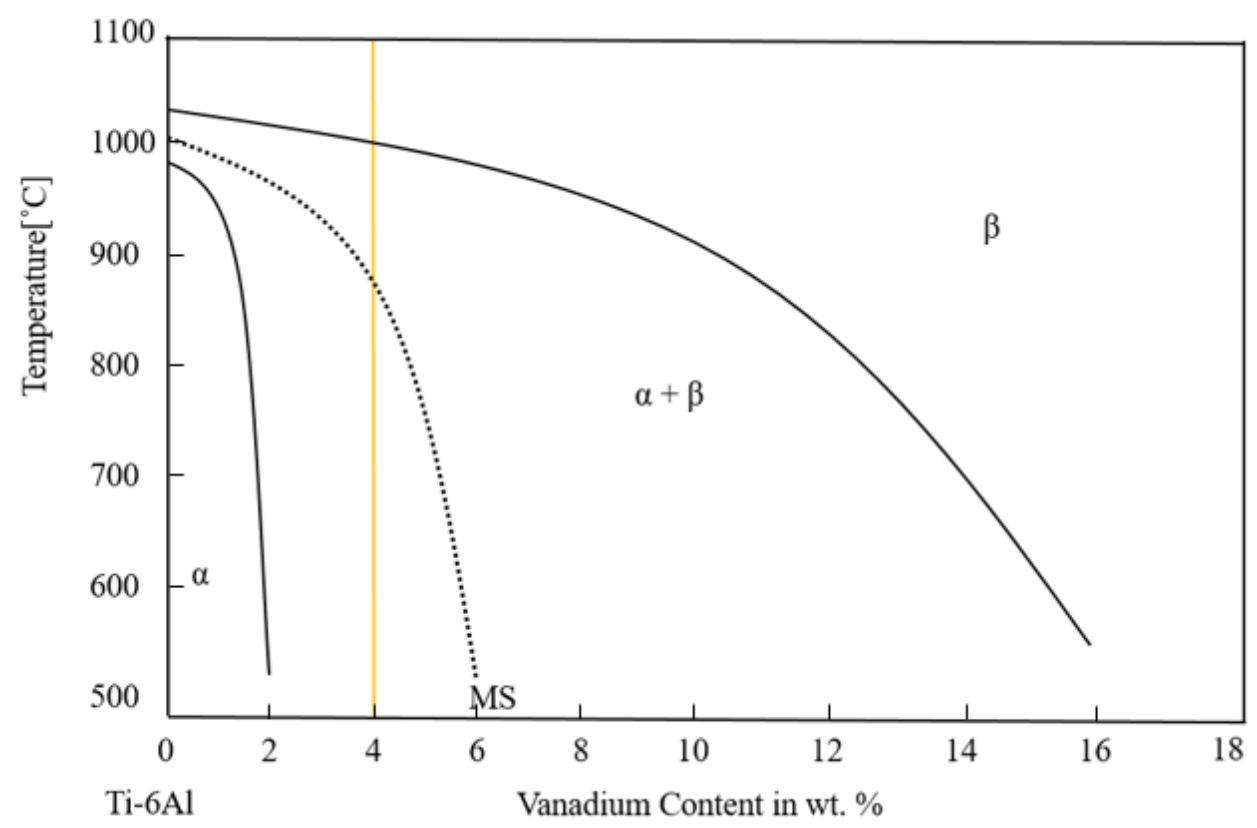

Figure 5. Schematic binary phase diagram of Titanium alloy. Reprinted with permission from [21].

\subsection{Hardness}

The hardness test was carried out by using the Vickers hardness measurement method (hardness tester HM-100, Mitutoyo, Kanagawa, Japan). This test was repeated five times in total. Figure 6 shows the hardness of the deposited titanium alloy specimens according to the conditions.

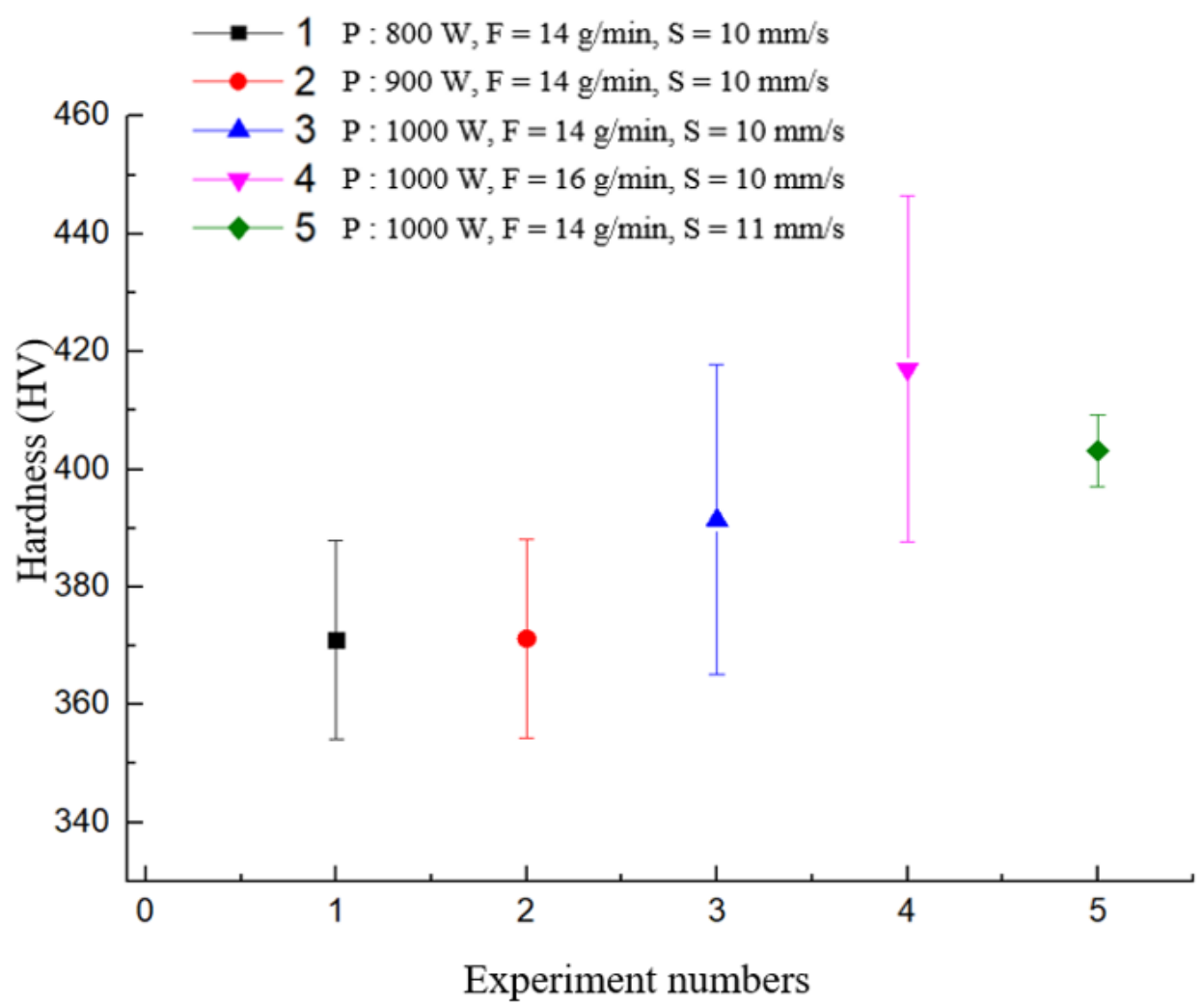

Figure 6. Hardness of deposited specimens according to condition. P: Laser power, F: powder feed rate, S: Scan speed. 
The deposited titanium alloy showed a tendency to harden more than the titanium alloy produced by the existing forging process. The hardening of deposited titanium alloy was thought to be caused by surface modification as a result of a high-power diode laser [22], which was the heat source, in the DED process. For Figure 4a, the average hardness value was approximately $363 \mathrm{HV}$. For Figure $4 \mathrm{~b}$, the average hardness value was approximately $368 \mathrm{HV}$. For Figure 4c, the average hardness value was approximately $389 \mathrm{HV}$. For Figure $4 d$, the average hardness value was approximately 419 HV. For Figure $4 \mathrm{e}$, the average hardness value was approximately $402 \mathrm{HV}$. After comparing the average values of all cases, it was found that a laser output from 8-900 W had a lower hardness than the conventional titanium alloy. It was determined that the titanium powder was not completely melted due to the low heating temperature. In addition, with a laser power of $1000 \mathrm{~W}$ and a scan speed of $10 \mathrm{~mm} / \mathrm{s}$, hardness values exceeding that of the existing titanium alloy were measured. The hardness of the titanium alloy produced by the forging process was approximately $349 \mathrm{HV}$.

\subsection{Thermal Analysis}

The governing equation of the thermal analysis is described by Equation (1) as follows:

$$
\frac{k}{\rho C}\left(\frac{\partial^{2} T}{\partial x^{2}}+\frac{\partial^{2} T}{\partial y^{2}}+\frac{\partial^{2} T}{\partial z^{2}}\right)+\dot{Q}=\frac{\partial T}{\partial t}
$$

where $C, k, t, T, \rho, \alpha$ and $\dot{Q}$ represent the density, specific heat, thermal conductivity, temperature, time, thermal diffusivity and power generation per unit volume, respectively. The initial condition at time $t=0$ is given by Equation (2) as follows:

$$
T(\mathrm{x}, \mathrm{y}, \mathrm{z}, 0)=T_{0}
$$

The boundary conditions can be defined by Equation (3) as follows:

$$
q(\mathrm{x}, \mathrm{y})-h\left(T-T_{0}\right)=-k \frac{\partial T}{\partial t}
$$

where $q, h, T$ and $T_{0}$ represent the heat flux, heat transfer coefficient, surface temperature and ambient temperature, respectively [23]. The finite element method (FEM) is used to predict actual process loads and results [24,25]. Figure 7 shows the 3D FEM model.

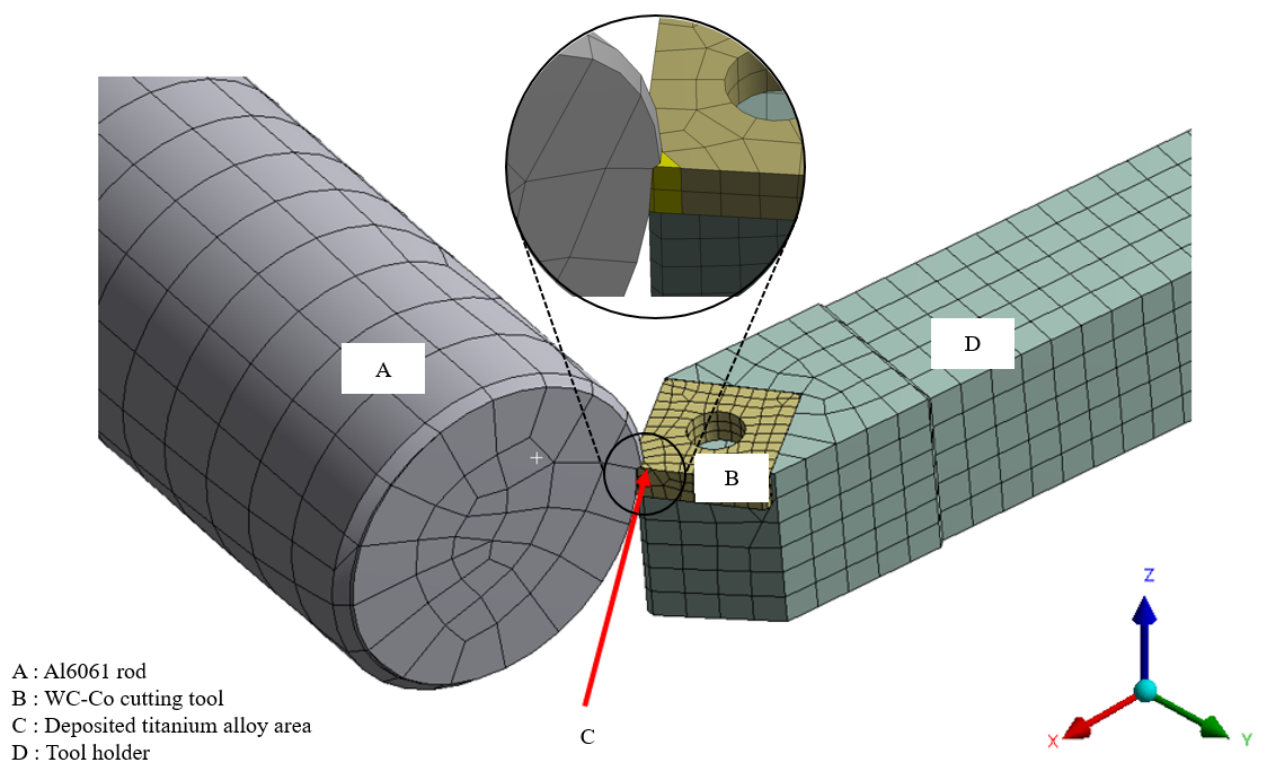

Figure 7. 3D model of the turning process for the FEM simulation. 
Thermal analysis was performed to predict the temperature distribution during the cutting process. The mesh of this model was an adapted hex-dominant method. The bottom side of the tool holder and one end of the Al6061 rod were fixed. The number of elements and nodes was 5676 and 23,902, respectively. The heat flow was applied to the cutting edge at $10 \mathrm{~W}$, considering the actual machining environment. The load of $10 \mathrm{~N}$ and Earth gravity were applied to the FE model. Fixed supported conditions were applied to the end of the workpiece and the tool holder. Table 3 shows the properties of the materials used in the FEM.

Table 3. Material properties.

\begin{tabular}{ccccc}
\hline Thermal Properties & Al6061 Rod & Ti-6Al-4V & Cutting Tool & Tool Holder \\
\hline Density $\left(\mathrm{g} / \mathrm{cm}^{3}\right)$ & 2.7 & 4.429 & 15.63 & 8.05 \\
Thermal conductivity & 167 & 6.7 & 110 & 45 \\
$(\mathrm{~W} / \mathrm{m} \cdot \mathrm{K})$ & 0.896 & 0.5263 & 292 & 420 \\
Specific heat $\left(\mathrm{J} / \mathrm{g} \cdot{ }^{\circ} \mathrm{C}\right)$ & &
\end{tabular}

All structures were subjected to a room temperature of $22^{\circ} \mathrm{C}$. The convection coefficient was set at $6 \mathrm{~W} / \mathrm{m}^{2}$. The temperature setting of the analytical model was recorded when the temperature was measured using a thermal imaging camera during the actual processing experiment. Figure 8 shows the results of the FEM analysis. The cutting edge of the WC-Co cutting tool insert deposited by AM of titanium alloy powder generates heat up to $116.53{ }^{\circ} \mathrm{C}$. Heat generation was highest at the contact surface with the Al6061 rod and gradually spread to the whole body. In an ordinary cutting tool insert, the highest temperature was observed at the contact surface with the Al6061 rod. The heat generation spreads from the contact surface with the Al6061 rod to the entire area of the cutting tool insert. The analysis result of the ordinary cutting tool insert was higher than the temperature of the cutting tool insert deposited by AM of titanium alloy powder. The heat generated at the cutting edge was measured to be $132.79{ }^{\circ} \mathrm{C}$. The heat generation of the ordinary cutting tool insert was measured to be approximately $13 \%$ higher than that of the cutting tool insert deposited by AM of titanium alloy powder.

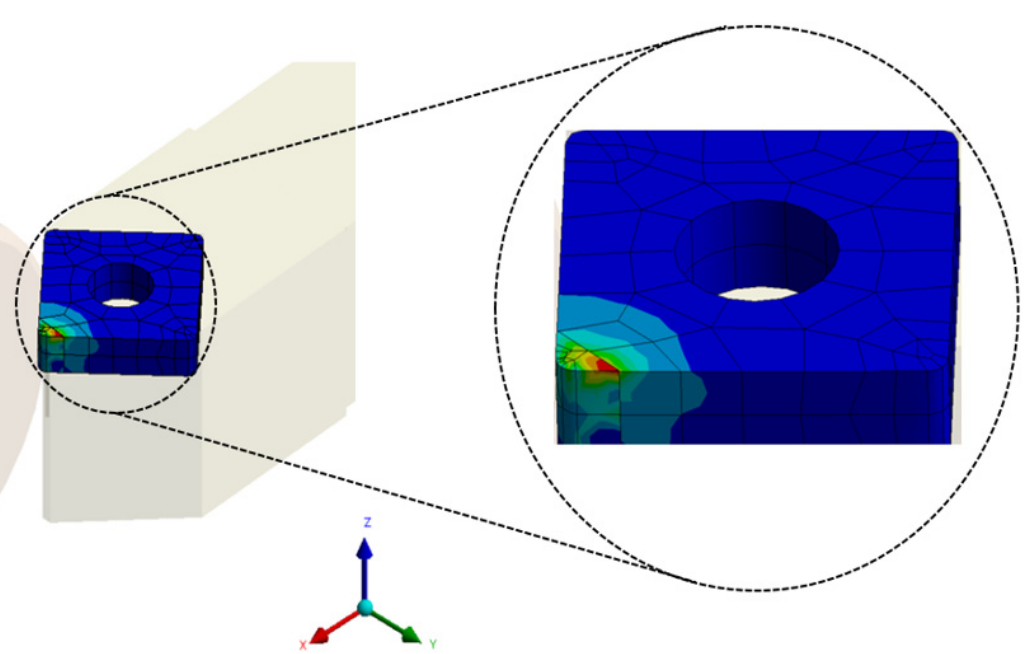

(a)

Figure 8. Cont. 

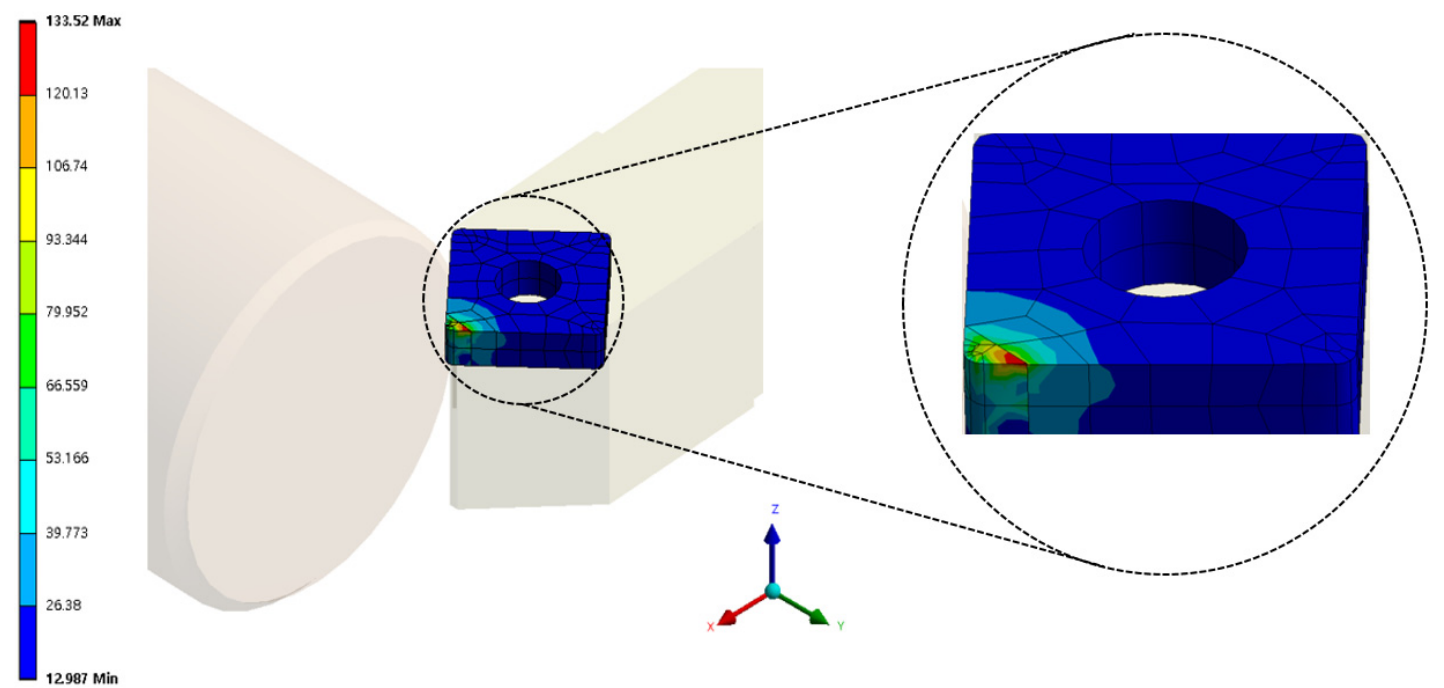

(b)

Figure 8. 3D model of the turning process for the FEM simulation: (a) temperature distribution of the cutting tool insert deposited by AM of titanium alloy powder; (b) temperature distribution of the ordinary cutting tool insert.

\section{Verification Experiments in Turning Process}

A computer numerically controlled (CNC) lathe was used for the turning tests. Figure 9a shows the CNC machine, and Figure $9 \mathrm{~b}$ shows the machining concept. The turning insert CNMG 120408 supplied by Daegu-tech ${ }^{\circledR}$ (Daegu, Korea) was used as the cutting tool insert. The machining characteristics of the turning process were compared. The turning process conditions were selected as the feed rate and cutting depth. The feed rate was selected with reference to the recommended machining conditions of the toolmaker. Al6061 rods were used as the cutting material, and the material had a yield strength of $48.3 \mathrm{GPa}$ and a modulus of elasticity of $68.9 \mathrm{GPa}$. A cutting experiment was conducted using a cutting tool insert deposited by AM of titanium alloy powder produced under five conditions and using an ordinary cutting tool insert. The experimental conditions were the same, i.e., a cutting speed of 710 RPM and a cut depth of $2 \mathrm{~mm}$. Dry cutting conditions were used to compare heat generation with ordinary cutting tool inserts. During the experiment, thermocouple measurement instruments were used to measure the heat generated during cutting. During cutting, the thermocouple measurement measures the temperature of the surface where the workpiece and the tool come into contact. One experiment was measured for about $30 \mathrm{~s}$. Figure 10 shows the temperature change over time of the Al6061 rod cutting experiments for the deposited, ordinary cutting tool insert. Section A is the start of processing, section B is the Al6061 rod deposited by AM of titanium alloy powder processing, and section C is the finish processing. The section measurement of the turning process was made from the moment the tool touched the Al6061 rod, and the cutting temperature was measured at intervals of $1 \mathrm{~s}$ to $21 \mathrm{~s}$ in the turning process. Section $\mathrm{A}$ is the starting section of the turning process. When processing begins in section A, the ordinary cutting tool insert begins to heat rapidly. In contrast, the cutting tool insert deposited by AM of titanium alloy powder heats relatively slowly. The ordinary cutting tool insert reaches the peak of the processing heat more rapidly than the cutting tool insert deposited by AM of titanium alloy powder. In section A, the difference in thermal conductivity between the cutting tool insert deposited by AM of titanium alloy powder and the common tool insert can be inferred. The ordinary cutting tool insert heats up faster. Moreover, the ordinary cutting tool insert has a higher thermal conductivity than the cutting tool insert deposited by AM of titanium alloy powder. In addition, section A exhibits the largest heating difference between the ordinary cutting tool insert and cutting tool insert deposited by AM of titanium alloy powder. Section B is the cutting tool insert for cutting the Al6061 rod. The highest cutting temperature in the section appears. In section $\mathrm{B}$, the cutting temperature of the 
heated ordinary cutting tool insert remains close to the peak. This result shows that, as observed in section A, the thermal conductivity of the cutting tool insert deposited by AM of titanium alloy powder was lower than that of the ordinary cutting tool insert. Section C shows the cooling process after the cutting process was conducted. The cutting tool insert deposited by AM of titanium alloy powder cools rapidly in section C, similar to section A. In addition, the rapidly cooled cutting temperature becomes cooler than the cutting tool insert deposited by AM of titanium alloy powder.

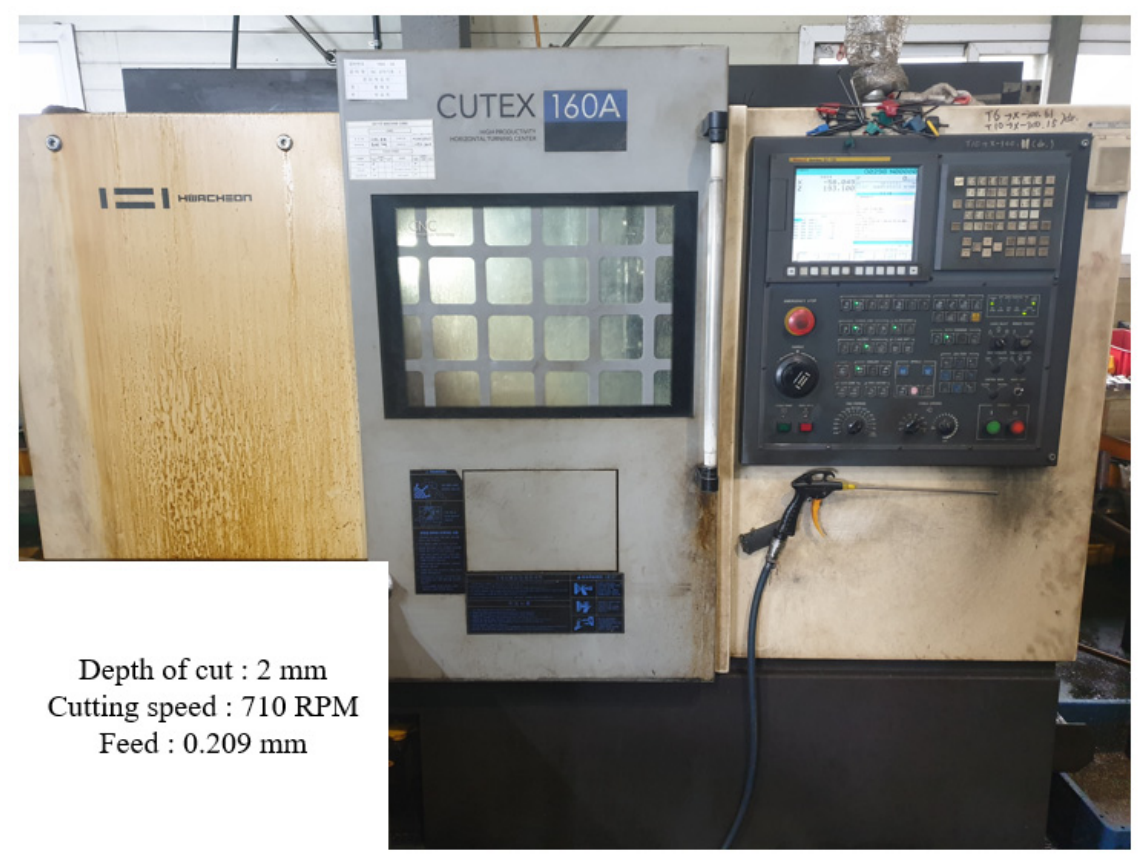

(a)

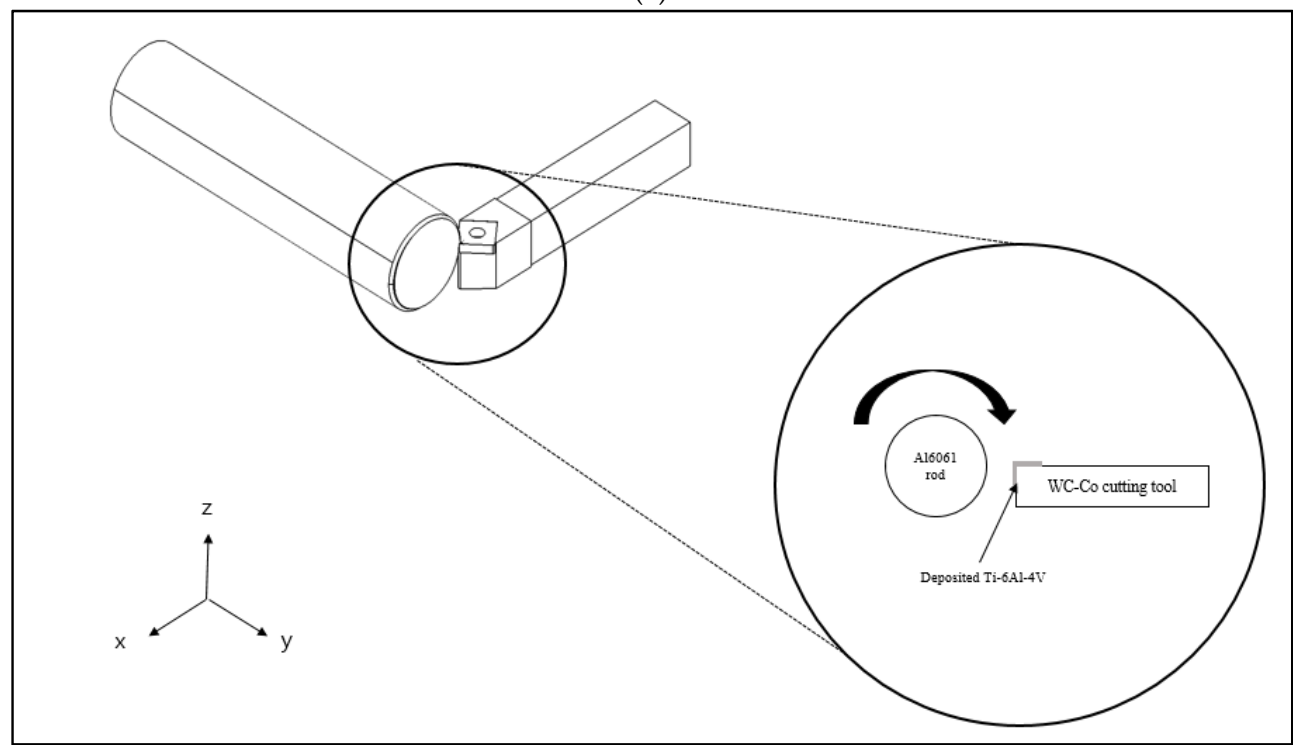

(b)

Figure 9. Titanium alloy deposited insert in the turning process: (a) CNC machine; (b) Schematic diagram of the turning process by the cutting tool insert deposited by AM of titanium alloy powder. 


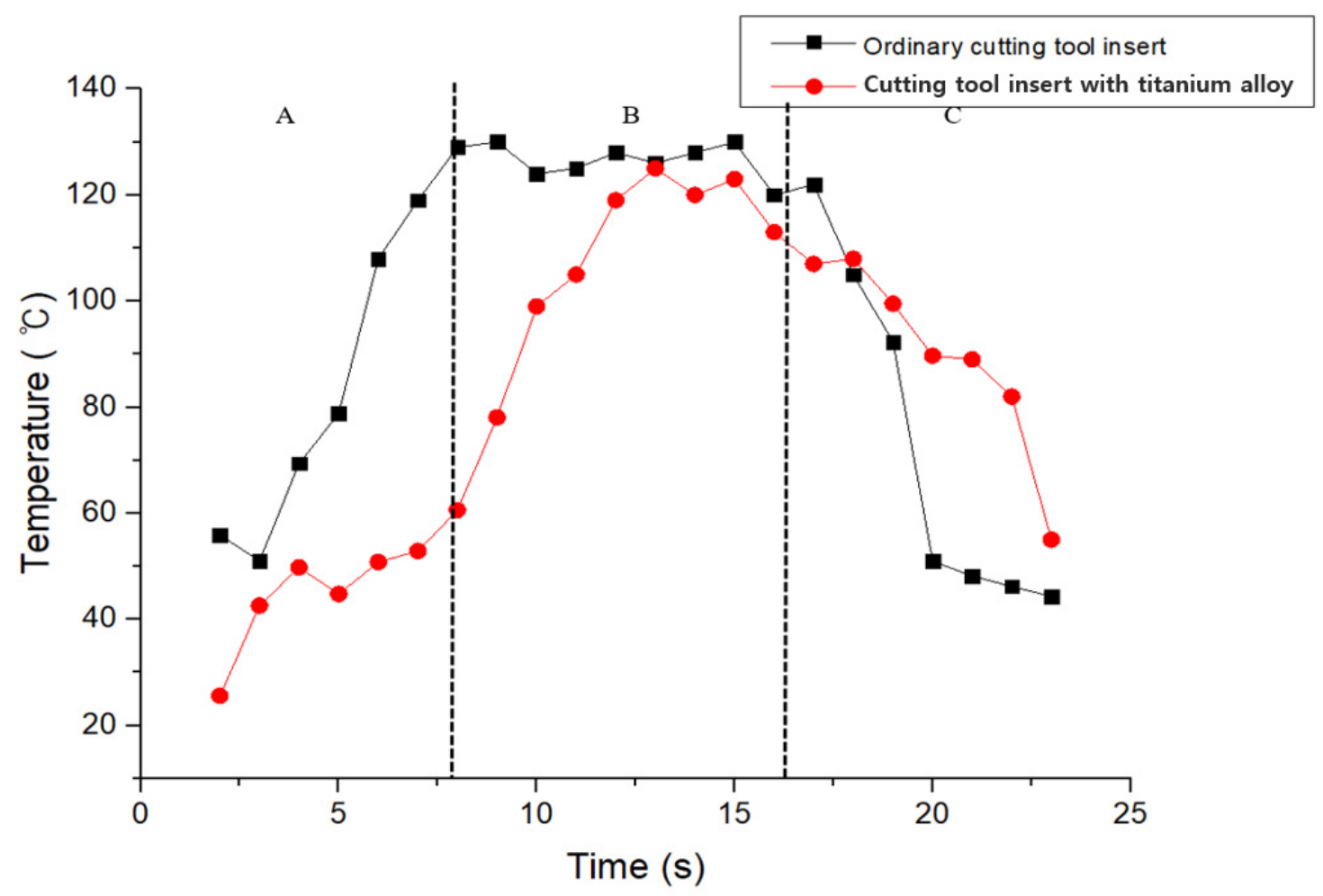

Figure 10. Comparison of the temperature changes between the ordinary cutting tool insert and cutting tool insert deposited by AM of titanium alloy powder.

In section C, the temperature of the cutting tool insert deposited by AM of titanium alloy powder was shown to gradually cool down as it intersects the temperature of the ordinary cutting tool insert. In addition, the average temperature at the start and processing time was higher in the ordinary cutting tool insert. The cutting tool insert deposited by AM of titanium alloy powder was found to cool more slowly during the cooling process after the cutting process. Heat generation during machining has been proven to promote wear and reduce tool life [26]. A comparison of heat generation during the cutting of the Al6061 rod using an ordinary cutting tool insert measured in this study and the cutting tool insert deposited by AM of titanium alloy powder was conducted. The results show an improvement in terms of the heat generated during the cutting process with the cutting tool insert deposited by AM of titanium alloy powder. The average temperature of the measured cutting tool insert deposited by AM of titanium alloy powder was approximately $15 \%$ lower than that of the ordinary cutting tool insert.

\section{Conclusions}

In this study, the thermal effect of a WC-Co cutting tool insert deposited by AM of titanium alloy powder was investigated. Preliminary experiments were performed to select the optimal deposition conditions, and then the selected conditions were used to produce a WC-Co cutting tool insert deposited by AM of titanium alloy powder. Thermal analysis and verification experiments were performed to predict and confirm the results. The main results of this study are as follows:

- Experiments were performed to determine the deposition conditions via the DED process of titanium alloy powder. Titanium alloy powder under the determined conditions was deposited on tungsten carbide tools. Postprocessing was performed to modify the cutting edge.

- Thermal analysis was performed to check the temperature distribution of the cutting tools. The temperature changes in the cutting tool insert deposited by DED of titanium alloy powder were calculated. The ordinary cutting tool insert was compared with the 
cutting tool insert deposited by DED of titanium alloy powder, and the results show that the average temperature of the latter was lower than that of the former under machining conditions. Thermal analysis showed that the maximum temperature of the cutting tool insert deposited by DED of titanium alloy powder was reduced by $13 \%$.

- Verification experiments were performed on a CNC turning machine. The cutting tool insert deposited by DED of titanium alloy powder shows a lower temperature than the ordinary cutting tool insert. The verification test results predicted that the tool life of the cutting tool insert deposited by DED of titanium alloy powder was longer than that of the ordinary cutting tool insert. The maximum temperature of the cutting tool insert deposited by DED of titanium alloy powder was reduced by $15 \%$ during machining.

Author Contributions: Conceptualization, J.-K.P. and D.-H.K.; methodology, J.-K.P.; software, J.-K.P.; validation, J.-K.P.; formal analysis, J.-K.P.; investigation, J.-K.P.; resources, J.-K.P.; data curation, J.-K.P.; writing—original draft preparation, J.-K.P. and D.-H.K.; visualization, J.-K.P.; writing-review and editing, D.-H.K., C.-M.L.; supervision, D.-H.K., C.-M.L.; project administration, J.-K.P., D.-H.K. and C.-M.L.; funding acquisition, C.-M.L. All authors have read and agreed to the published version of the manuscript.

Funding: This work was supported by the National Research Foundation of Korea (NRF) grant funded by the Korea government (MSIT) (No. 2019R1A2B5B03070206).

Data Availability Statement: Data presented in this article are available at request from the corresponding author.

Conflicts of Interest: The authors declare no conflict of interest.

\section{References}

1. Traxel, K.D.; Bandyopadhyay, A. First Demonstration of Additive Manufacturing of Cutting Tools using Directed Energy Deposition System: StelliteTM-Based Cutting Tools. Addit. Manuf. 2019, 25, 460-468. [CrossRef]

2. Klocke, F.; Arntz, K.; Teli, M.; Winands, K.; Wegener, M.; Oliari, S. State-of-the-art Laser Additive Manufacturing for Hot-work Tool Steels. Procedia CIRP 2017, 63, 58-63. [CrossRef]

3. Manfredi, D.; Calignano, F.; Ambrosio, E.P.; Krishnan, M.; Canali, R.; Biamino, S.; Pavese, M.; Atzeni, E.; Luliano, L.; Fino, P.; et al. Direct Metal Laser Sintering: An additive manufacturing technology ready to produce lightweight structural parts for robotic applications. Metall. Ital. 2013, 10, 15-23.

4. Azarniya, A.; Colera, X.G.; Mirzaali, M.J.; Sovizi, S.; Bartolomeu, F.; St Weglowski, M.K.; Wits, W.W.; Yap, C.Y.; Ahn, J.; Miranda, G.; et al. Additive manufacturing of Ti-6Al-4V parts through laser metal deposition (LMD): Process, microstructure, and mechanical properties. J. Alloys Compd. 2019, 804, 163-191. [CrossRef]

5. Wolff, S.J.; Lin, S.; Faierson, E.J.; Liu, W.K.; Wagner, G.J.; Cao, J. A framework to link localized cooling and properties of directed energy deposition (DED)-processed Ti-6Al-4V. Acta Mater. 2017, 132, 106-117. [CrossRef]

6. Traxel, K.D.; Bandyopadhyay, A. Diamond-reinforced cutting tools using laser-based additive manufacturing. Addit. Manuf. 2021, 37, 101602. [CrossRef]

7. Leal, R.; Barreiros, F.M.; Alves, L.; Romeiro, F.; Vasco, J.C.; Santos, M.; Marto, C. Additive manufacturing tooling for the automotive industry. Int. J. Adv. Manuf. Technol. 2017, 92, 1671-1676. [CrossRef]

8. Fotovvati, B.; Asadi, E. Size effects on geometrical accuracy for additive manufacturing of Ti-6Al-4V ELI parts. Int. J. Adv. Manuf. Technol. 2019, 104, 2951-2959. [CrossRef]

9. Ma, J.; Duong, N.H.; Lei, S. 3D numerical investigation of the performance of microgroove textured cutting tool in dry machining of Ti-6Al-4V. Int. J. Adv. Manuf. Technol. 2015, 79, 1313-1323. [CrossRef]

10. Guimarães, B.; Fernandes, C.M.; Figueiredo, D.; Cerqueira, M.F.; Carvalho, O.; Silva, F.S.; Miranda, G. A novel approach to reduce in-service temperature in WC-Co cutting tools. Ceram. Int. 2020, 46, 3002-3008. [CrossRef]

11. Kustas, F.M.; Fehrehnbacher, L.L.; Komanduri, R. Nanocoatings on cutting tools for dry machining. CIRP Ann.-Manuf. Technol. 1997, 46, 39-42. [CrossRef]

12. List, G.; Nouari, M.; Géhin, D.; Gomez, S.; Manaud, J.P.; Le Petitcorps, Y.; Girot, F. Wear behaviour of cemented carbide tools in dry machining of aluminium alloy. Wear 2005, 259, 1177-1189. [CrossRef]

13. Kim, D.H.; Kim, T.J.Y.; Wang, X.; Kim, M.; Quan, Y.J.; Oh, J.W.; Min, S.H.; Kim, H.; Bhandari, B.; Yang, I.; et al. Smart Machining Process Using Machine Learning: A Review and Perspective on Machining Industry. Int. J. Precis. Eng. Manuf. -Green Technol. 2018, 5, 555-568. [CrossRef]

14. Devaraj, S.; Malkapuram, R.; Singaravel, B. Performance analysis of micro textured cutting insert design parameters on machining of Al-MMC in turning process. Int. J. Light. Mater. Manuf. 2021, 4, 210-217. 
15. Yan, S.; Kong, J.; Sun, Y. Continuum model based chatter stability prediction for highly flexible parts in turning process with accurate dynamic force modeling. J. Manuf. Process. 2021, 62, 221-233. [CrossRef]

16. Kam, M.; Demirtaş, M. Analysis of tool vibration and surface roughness during turning process of tempered steel samples using Taguchi method. Proc. Inst. Mech. Eng. Part E J. Process Mech. Eng. 2021, 235, 5. [CrossRef]

17. Franchi, R.; Giannuzzi, M.; Papadia, G. Thermal characterization methodology for dry finishing turning of SAF 2507 stainless steel based on finite element simulations and surrogate models. Procedia CIRP 2019, 82, 383-388. [CrossRef]

18. Gupta, M.K.; Song, Q.; Liu, Z.; Sarikaya, M.; Mia, M.; Jamil, M.; Singla, A.K.; Bansal, A.; Pimenov, D.Y.; Kuntoğlu, M. Tribological performance based machinability investigations in cryogenic cooling assisted turning of $\alpha$ - $\beta$ titanium Alloy. Tribol. Int. 2021, 160, 107032. [CrossRef]

19. Kolluri, A.P.; Balla, S.P.; Paruchuru, S.P. Evaluation of thermal effects in turning processes: Numerical and experimental approach. In Proceedings of the IMECE, Salt Lake City, UT, USA, 11-14 November 2019.

20. Reda, R.; Hussein, A.-H.; Nofal, A.; Sobih, M.; El-Banna, E.-S.M. Effect of welding processes and postweld heat treatment on the mechanical properties of ti-6al-4v castings. Int. J. Mater. Eng. Technol. 2015, 13, 1-21. [CrossRef]

21. Swarnakar, A.K.; Van Der Biest, O.; Baufeld, B. Thermal expansion and lattice parameters of shaped metal deposited Ti-6Al-4V. J. Alloys Compd. 2011, 509, 2723-2728. [CrossRef]

22. De Damborenea, J. Surface modification of metals by high power lasers. Surf. Coatings Technol. 1998, 100-101, 377-382. [CrossRef]

23. Woo, W.S.; Lee, C.M. Innovative use of multi-heat sources for improvement of tool life in thermally assisted machining of high-strength material. J. Manuf. Process. 2019, 38, 30-37. [CrossRef]

24. Song, S.H.; Choi, W.C. FEM analysis on the influence of rounded tool edge on micro-blanking of thin foil with negative clearance. Int. J. Precis. Eng. Manuf. 2015, 16, 1101-1105. [CrossRef]

25. Jung, Y.S.; Gao, J.C.; Lee, G., II; Jung, K.R.; Kim, J.Y. Large Curvic Coupling Gear for Ultraprecision Angle Division Using FEM. Int. J. Precis. Eng. Manuf. 2021, 22, 495-503. [CrossRef]

26. Wang, Q.; Jin, Z.; Zhao, Y.; Niu, L.; Guo, J. A comparative study on tool life and wear of uncoated and coated cutting tools in turning of tungsten heavy alloys. Wear 2021, 9, 203929. [CrossRef] 